\title{
ÉTUDES HISTOLOGIQUES
}

\author{
BUR LE

\section{LABYRINTHE MEMBRANEUX}

ET PLUS SPECIALEMENT 8UR LE

\section{LIMACON CEBL LES REPTILES ET LES OISEAUX}

PAR

\author{
PAUL MEYER
}

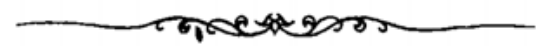

STRASBOURG

CH. J. TRÜBNER, LIBRAIRE-ÉDITEUR

PARIS

J. B. BAILLIËRE ET FILS

1876 

Monsieur le professeur W ALDEYER

P. MEYER. 
A MON PĖRE

Docteur en médecine à Fegersheim.

P. MEYER. 